\title{
Cotxets de joguina: una eina estimulant per estudiar el moviment
}

\author{
Sònia Bofill Ayuda i María Isabel Lacasa Millán \\ IES Joaquima Pla i Farreras, Sant Cugat del Vallès \\ soniabofill@yahoo.com; mlacasa3@xtec.cat
}

Sovint és difícil trobar material senzill $i$ assequible amb què poder fer pràctiques de cinemàtica a primer cicle de l'ESO. Aquest article descriu l'experiència realitzada amb alumnes de $2 n$ d'ESO per estudiar el moviment rectilini $i$ uniforme fent servir un recurs tan a l'abast com és un cotxet de joguina. D'aquesta manera la recollida de les dades necessàries per calcular les velocitats i construir les gràfiques corresponents es realitza d'una forma molt engrescadora per als alumnes.

Paraules clau: cinemàtica, moviment rectilini uniforme, 2n ESO, cotxet de joguina

\section{Introducció}

A l'hora de treballar amb els conceptes abstractes -i la cinemàtica ho és força per als alumnes de primer cicle de l'ESO- recórrer a situacions o fets propers a la seva experiència personal no només suposa estar en sintonia amb el desenvolupament del nou currículum per competències sinó que és realment efectiu.

Descrivim a continuació una experiència senzilla que hem posat en pràctica aquest curs en la que els alumnes de segon d'ESO poden estudiar, prenent les dades necessàries i fent els càlculs adients, un moviment rectilini amb una velocitat aproximadament constant.

El material amb el qual es pot dur a terme l'activitat està a l'abast de tothom, amb l'avantatge que els permet fer-se una representació real del concepte teòric que estan estudiant, a més d'aprendre a realitzar un tractament bàsic de l'error associat a les mesures experimentals.

\section{Objectius de la pràctica i competències que es treballen}

Els objectius que es pretenen amb la pràctica i que es fan explícits als alumnes al començament són:
- Estudiar, de forma pràctica, el moviment rectilini i uniforme d'un mòbil

- Calcular la velocitat mitjana d'un mòbil a partir de la presa de dades de la posició i del temps

- Construir, a partir de dades reals, els gràfics posició-temps i velocitat-temps

- Entendre el concepte d'error de mesura i detectar els que s'han comès

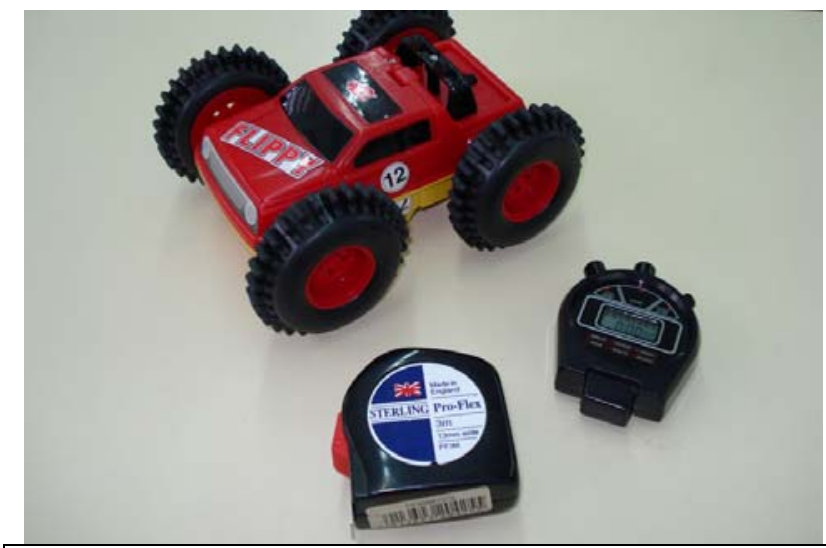

Figura 1. Material necessari per dur a terme la pràctica.

Amb aquests objectius es pretén treballar la competència científica, que és la competència més característica de la nostra matèria; però també punts essencials de les competències comunicati- 
ves, metodològiques (sobretot la competència matemàtica) i personals.

\section{Material necessari}

El material necessari per al desenvolupament de la pràctica és el següent (fig. 1):

- Un cotxet de joguina que es desplaci en línia recta i a una velocitat prou constant

- Un cronòmetre

- Una cinta mètrica

\section{Contextualització de l'activitat}

Nosaltres vam fer la pràctica en el laboratori però també podria fer-se en un altre espai, sempre que hi hagués una superfície llisa de uns dos metres de longitud sobre la qual pogués desplaçar-se el cotxet.

Considerem que és preferible que l'experiència es dugui a terme un cop els alumnes "dominin" els conceptes que són la base teòrica de l'activitat per tal que aquesta els serveixi de síntesi i reflexió sobre el que han estudiat a l'aula.

Recomanem que el nombre d'alumnes sigui reduït (nosaltres vam fer servir les hores de desdoblament) per tal que treballin per parelles (màxim en grups de tres) i el professorat pugui atendre adequadament els diferents grups. També perquè cada grup pugui disposar de tot el material necessari i tots els alumnes del grup tinguin un paper actiu en el desenvolupament de la pràctica.

En el nostre cas, com que els grups-classe de segon d'ESO eren de 26-28 alumnes, el nombre de grups que havíem d'atendre cada cop era de sis, prou assequible per realitzar una atenció individualitzada durant tot el procés.

\section{Procediment experimental}

Aquesta activitat es pot dividir en dues parts que poden durar una o dues sessions. La primera s'ha de dur a terme al laboratori o a l'espai preparat a l'efecte. La segona es pot fer a l'aula o es pot demanar com a deures per a casa, però en tots dos casos cal fer una posada en comú i unes consideracions finals.

La primera part correspon a la realització d'unes preguntes prèvies que permetin als alumnes situarse a la pràctica i recordar el que s'ha treballat a l'aula anteriorment, la construcció del muntatge experimental i la recollida de dades.
La segona part es dedica al tractament de les dades i l'elaboració de gràfiques, el llistat de material utilitzat, l'explicació del procediment experimental, la resolució d'algunes qüestions i la formulació de les conclusions.

Passem a explicar, ara, les diferents etapes del procés.

\section{Treball inicial}

Es reparteix el guió de l'activitat, es comenten els objectius, es fan les activitats prèvies i es deixa un temps per tal que pensin com desenvolupar l'experiència $\mathrm{i}$ quin material necessitaran per dur-la a terme.

\section{Muntatge experimental i recollida de dades}

Es fa una posada en comú del material necessari i com haurà de ser el muntatge experimental. Seguidament es procedeix a dur a terme l'activitat.

En el nostre cas, els alumnes marcaven a la superfície de treball posicions distanciades entre si 20 cm (va ser la distància de separació que ells van triar més sovint). La majoria indicaven amb llapis o bolígrafs aquestes posicions (fig. 2a).

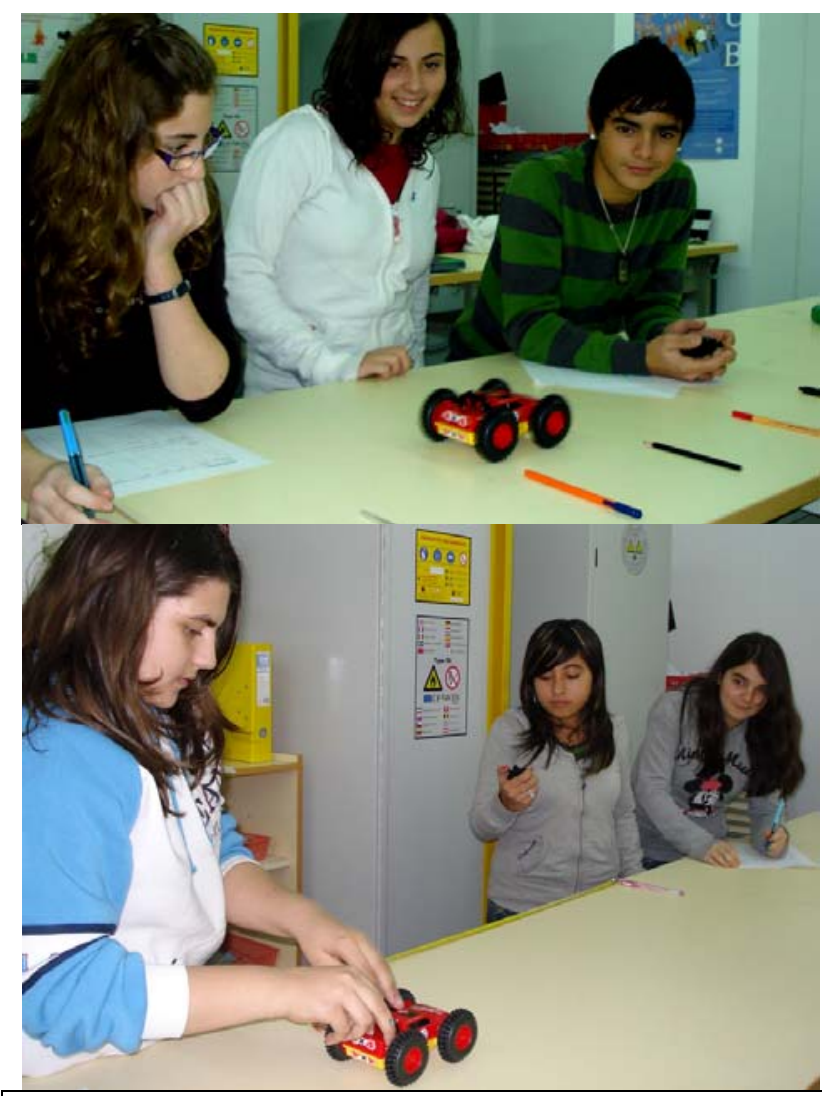

Figures 2a, 2b. Alumnes durant el desenvolupament de l'experiència pràctica. 
Un cop marcades les posicions, cronometraven el temps que trigava el cotxet en recórrer la distància des de la primera marca -posició inicial- fins a cada una de les marques posteriors (fig. 2b). La mesura del temps invertit en recórrer les diferents distàncies es repetia tres vegades, ja que així les sèries de mesures permetien després abordar el concepte d'error de mesura, associat a qualsevol presa de dades.

\section{Recollida de dades}

Anota totes les dades que et demanen en el quadre:

\begin{tabular}{|c|c|c|c|c|c|}
\hline $\begin{array}{c}\text { Posició inicial } \\
(\mathrm{cm})\end{array}$ & $\begin{array}{c}\text { Posició final } \\
(\mathrm{cm})\end{array}$ & $\begin{array}{c}\text { Temps } 1 \\
(\mathrm{~s})\end{array}$ & $\begin{array}{c}\text { Temps } 2 \\
(\mathrm{~s})\end{array}$ & $\begin{array}{c}\text { Temps 3 } \\
(\mathrm{s})\end{array}$ & Temps mig (s) \\
\hline 0 & $20 \mathrm{~cm}$ & 0,66 & 0,60 & 0,66 & 0,64 \\
\hline 0 & $40 \mathrm{~cm}$ & 1,32 & 1,22 & 1,28 & 1,27 \\
\hline 0 & $60 \mathrm{~cm}$ & 1,87 & 1,84 & 1,88 & 1,87 \\
\hline 0 & $80 \mathrm{~cm}$ & 2,62 & 2,66 & 2,66 & 2,64 \\
\hline 0 & $100 \mathrm{~cm}$ & 3,25 & 3,29 & 3,19 & 3,24 \\
\hline 0 & $120 \mathrm{~cm}$ & 3,81 & 3,66 & 3,79 & 3,75 \\
\hline 0 & $140 \mathrm{~cm}$ & 4,43 & 4,54 & 4,60 & 4,52 \\
\hline
\end{tabular}

Figura 3. Taula amb les dades recollides per un grup d'alumnes.

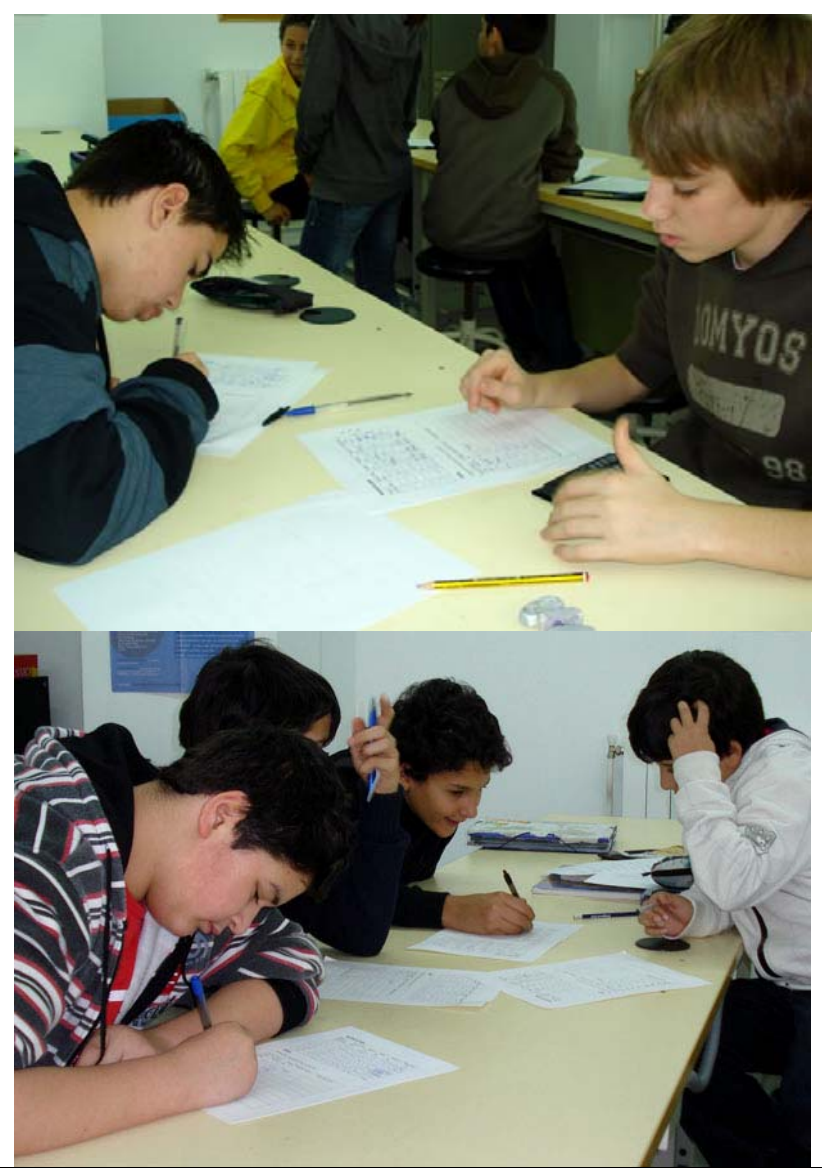

Figures 4a, 4b. Alumnes fent el tractament de les dades
Totes les dades recollides es van anotant en una taula. També es calcula i anota a la mateixa taula el temps mitjà per a cada distància (fig. 3).

\section{Tractament de les dades}

Un cop recollides les dades, és el moment de treballar-les (fig. 4). Per aconseguir-ho cal que omplin una segona taula fent tots els càlculs necessaris per confeccionar les gràfiques posició-temps i velocitat-temps i realitzar posteriorment la seva anàlisi (fig. 5).

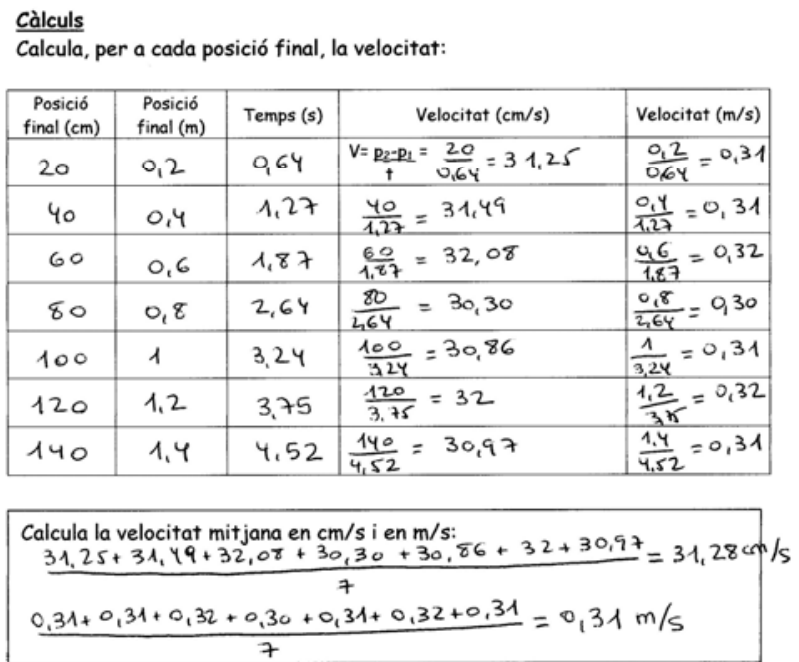

Figura 5. Taula de tractament de dades.

\section{Representacions gràfiques}

Els alumnes han de construir dues gràfiques amb les seves dades. Ho poden fer en paper mil-limetrat o utilitzant un full de càlcul.

A la gràfica posició-temps, cal que representin les posicions en centímetres a l'eix d'abscisses i el temps en segons a l'eix d'ordenades.

$\mathrm{Si}$ ja han treballat els conceptes de variable independent i dependent, com era el nostre cas, han de ser ells qui decideixin on col-locar cada paràmetre. A la gràfica velocitat-temps, representen les velocitats en $\mathrm{cm} / \mathrm{s}$ a l'eix d'abscisses i el temps, en segons, a l'eix d'ordenades. (fig. 6)

El gràfic posició-temps acostuma a donar com a resultat una recta amb pendent positiu bastant ajustada, a partir de la qual es pot deduir que la velocitat és constant, i es pot calcular el seu valor.

Del gràfic velocitat-temps, resulta una recta horitzontal amb els punts bastant alineats, però s'ha d'anar amb compte, a l'hora de la representació i que a l'eix d'abscisses l'escala de velocitats no sigui massa petita per no fer massa evident el possi- 
ble error experimental i que això els condueixi a conclusions errònies.

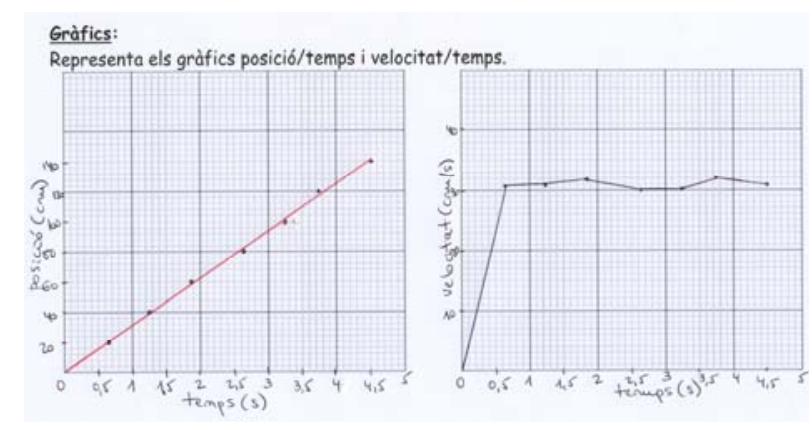

Figura 6. Gràfics corresponents a les dades de la taula de la figura 5

\section{Preguntes finals i elaboració de conclusions}

Per tal de cimentar els conceptes treballats, comprovar l'assoliment dels objectius i ajudar a treure conclusions, es proposem unes preguntes finals en les quals també hi ha un parell d'exercicis en què han de fer servir les dades obtingudes per a resoldre'ls.

Finalment han de treure les conclusions a les què han arribat durant el transcurs de l'experiència. És convenient guiar-los en aquesta última activitat de forma que no es limitin a fer un resum de la pràctica sinó que les conclusions resultin d'una reflexió de la feina feta.

\section{Consideracions finals i possibilitats d'ampliació}

A l'hora de comprar el cotxet cal assegurar-se que aquest es desplaça en línia recta i a una velocitat, pràcticament, constant. Nosaltres vam trobar algunes dificultats per aconseguir un model que s'adaptés a les nostres necessitats.

És important remarcar que el cotxet s'ha d'engegar abans de la posició inicial, que sempre serà la mateixa, i que s'ha de prendre com a referència sempre el mateix punt del cotxe (per exemple, engegar i parar el cronòmetre quan la roda davantera passi per la marca que indica la posició exacta). També cal que cronometri sempre la mateixa persona, per minimitzar errors.

Durant el desenvolupament de la pràctica vam comprovar que resultava molt més còmode, per als alumnes, repetir la mesura de cada distància tres vegades abans de passar a cronometrar la distància següent.

Les variacions en els resultats de la mesura del temps permeten introduir el concepte d'error de mesura i desenvolupar-lo més o menys en funció de les característiques del grup. Reflexionar sobre l'error experimental en la presa de dades hem vist que representa per als alumnes tot un descobriment ja que molts no havien pensat mai que es poden equivocar quan mesuren alguna cosa.

Així mateix, és important explicar bé com s'han de realitzar les gràfiques i com fer la seva interpretació. Sovint els alumnes conclouen que la velocitat no és constant perquè no obtenen una "recta perfecta" en el gràfic posició-temps. Fins i tot, si el grup ho permet, es pot introduir, sense donar-li nom, el concepte de recta de regressió.

Creiem que aquesta mateixa pràctica, amb lleugeres modificacions, podria aplicar-se a segon cicle. En aquest cas, considerem convenient utilitzar l'equip Multilog amb el sensor de velocitat, ja que permetria una recollida i tractament de les dades molt més acurats.

Finalment, volem comentar que hem treballat aquesta activitat amb els quatre grups de segon d'ESO del nostre centre, cosa que representa 110 alumnes i que tant a nivell personal com pels comentaris dels alumnes, els resultats de l'experiència han estat molt positius.

El guió en format PDF d'aquesta pràctica es pot obtenir a la secció Suplement d'aquest número de la revista Ciències. 